I nvest i gat i on of i r radi at i on effect s on hi ghl y i nt egr at ed I eadi ng- edge el ect r oni c component s of di agnostics and control systems for LHD deut er i um oper at i on

\begin{tabular}{|l|l|}
\hline $\begin{array}{l}\text { j our nal or } \\
\text { publ i cat } i \text { on } \mathrm{ti} \text { t l e }\end{array}$ & Nucl ear Fusi on \\
\hline vol une & 57 \\
\hline number & 8 \\
\hline page $\mathrm{r}$ ange & 086012 \\
\hline year & $2017-06-14$ \\
\hline URL & ht t p: //hdl . handl e. net /10655/00012566 \\
\hline
\end{tabular}




\title{
Investigation of irradiation effects on highly integrated leading edge electronic components of diagnostics and control systems for the LHD deuterium operation
}

K. Ogawa ${ }^{1,2}$, T. Nishitani ${ }^{1}$, M. Isobe ${ }^{1,2}$, I. Murata ${ }^{3}$, Y. Hatano ${ }^{4}$, S. Matsuyama ${ }^{5}$, H.

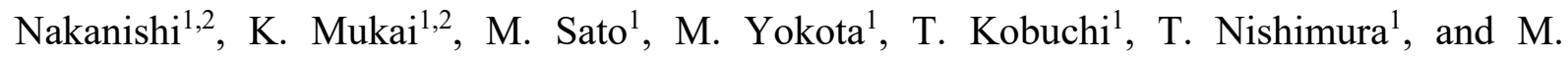
Osakabe $e^{1,2}$

${ }^{1}$ National Institute for Fusion Science, National Institutes of Natural Sciences, Toki, 5095292, Japan

${ }^{2}$ SOKENDAI (The Graduate University for Advanced Studies), Toki, 509-5292, Japan

${ }^{3}$ Osaka University, Yamada-oka 2-1, Suita, Osaka 565-0871, Japan

${ }^{4}$ University of Toyama, Gofuku 3190, Toyama 930-8555, Japan

${ }^{5}$ Tohoku University, Aramaki-Aza-Aoba 01, Aoba-ku, Sendai 980-8579, Japan

E-mail contact of main author: kogawa@nifs.ac.jp

\begin{abstract}
High-temperature and high-density plasmas are achieved by means of real time control, fast diagnostic, and high power heating systems. Those systems are precisely controlled by means of highly integrated electronic components. However, the radiation damage leads to serious impact on those systems. Therefore, the effects due to irradiation on electronic components being used currently should be investigated for control and measurement of Large Helical Device (LHD) deuterium plasmas. For precise estimation of the radiation field in the LHD torus hall, MCNP6 code is used with the cross-section library of ENDF B-VI. The
\end{abstract}


geometry is modeled based on the CAD drawing. The dose on silicon, which is a major ingredient of electronics components, during the nine years of the LHD deuterium operation shows that the gamma-ray contributions are dominant in dose. Neutron irradiation tests are performed in the OKTAVIAN at Osaka University and the Fast Neutron Laboratory at Tohoku University. Also gamma-ray irradiation tests are performed in the Nagoya University Cobalt-60 irradiation facility. We found that there are Ethernet connection failures of programmable logic controller (PLC) modules due to neutron irradiation with neutron flux of $3 \times 10^{6} \mathrm{~cm}^{-2} \mathrm{~s}^{-1}$. The neutron flux is equivalent to the flux expected at the basement level in the LHD torus hall without a neutron shield. Most modules of the PLC are broken around the gamma-ray dose of 100 Gy. This is comparable with the dose in the LHD torus hall over nine years. Finally, if we consider the dose only, these components may survive more than nine years. For the safety of the LHD operation, electronic components placed in the torus hall have been rearranged.

\section{Introduction}

High performance plasmas are achieved by means of real time control, fast diagnostic, and high power heating systems. Those systems are precisely controlled by means of transmission and highly integrated electronic components. However, the radiation damage due to neutron and/or gamma-ray may lead to serious impact on those systems. For example, due to the increase of background level of microchannel-plate electron multipliers (MCPs) by radiation, the dynamic range of an MCP detector reduces to the point of uselessness in TFTR [1]. In JET, numbers of dead pixels on imaging camera increased linearly as the increase of the neutron fluence [2]. To investigate the effect of neutrons or gamma-rays on those components, irradiation tests were intensively performed in the 1990s in irradiation facilities such as the Fusion Neutronics Source [3] at the Japan Atomic Energy Agency and OKTAVIAN [4] at Osaka University. It is reported that a programmable logic controller (PLC) was broken by 1000 Gy gamma-ray irradiation [5]. At present, though the radiation resistance of transmission components has not changed significantly, the radiation resistance of electronic components might change because of higher integration of integrated circuits 
compared with integrated circuits of more than 20 years ago. Deuterium operation will be started from 2017 on the Large Helical Device (LHD) and continues for nine years. LHD is controlled by means of many semiconductor integrated circuits placed around LHD in the torus hall with remote control capability. These circuits are regularly replaced with the newest highly-integrated circuit. The integration of the electronic circuit becomes higher, which means that the number of atoms inside one chip is reduced and the operational voltage inside the circuit becomes lower. Therefore, the damage due to a neutron and/or gamma-ray on an atom can easily cause a problem compared with the electronic circuit with lower integration. Thus, the circuits become weaker against the radiation because of the higher integration. Therefore, the effects due to irradiation on electronic components being used currently should be investigated for control and measurement of LHD deuterium plasmas.

\section{Neutron and gamma-ray transport calculation in LHD}

For precise estimation of the radiation field in the LHD torus hall, MCNP6 three-dimensional Monte-Carlo neutronics code [6] is used with the cross-section library of ENDF B-VI [7]. In the MCNP calculation geometry, the LHD components within the support structure are divided by small toroidal angle pitch, and the components are assumed to be toroidally symmetric in a toroidal pitch angle. The geometry in one toroidal pitch angle is modelled based on the CAD drawing with some simplification (Fig. 1). The neutron source is isotropic and homogeneous in the torus with the energy of $2.45 \mathrm{MeV}$. A three-dimensional map of the radiation field in the LHD torus hall has been obtained. Figure 2 a shows the neutron flux profile in the LHD torus hall and the profile in the basement level of the torus hall at the maximum neutron emission discharge (total neutron emission rate of $1.9 \times 10^{16} \mathrm{~s}^{-1}$ ). It is found that the neutron flux in the torus hall, and the flux in the basement level are around $10^{9} \mathrm{~cm}^{-2} \mathrm{~s}^{-1}$ and around $10^{6} \mathrm{~cm}^{-2} \mathrm{~s}^{-1}$, respectively. Figure $2 \mathrm{~b}$ shows the profiles of the dose on silicon ( $\left.\mathrm{Si}\right)$, 
which is a major ingredient of electronics components, during the nine years of the LHD deuterium operation. The gamma-ray contributions are dominant in dose.

\section{Neutron irradiation test}

To investigate the irradiation effect on electronic components used in the LHD torus hall, neutron irradiation tests are performed in the Fast Neutron Laboratory (FNL) at Tohoku University [10] and OKTAVIAN [11]. A PC, a media converter, an infrared (IR) camera, a multi-pixel photon counter (MPPC), a web camera, two avalanche photodiode (APDs), two photomultiplier tubes (PMTs), and PLCs are tested (Fig. 3). In the experiment performed in OKTAVIAN, the total neutron emission rate from the target is up to $9 \times 10^{8} \mathrm{~s}^{-1}$, therefore, the neutron flux at $5 \mathrm{~cm}$ away from the target, and the flux at $10 \mathrm{~cm}$ away from the target are up to $3 \times 10^{6} \mathrm{~cm}^{-2} \mathrm{~s}^{-1}$ and $7 \times 10^{5} \mathrm{~cm}^{-2} \mathrm{~s}^{-1}$, respectively. The neutron exposure has been performed for 11.5 hours. The neutron flux in this experiment is two or three orders smaller than the neutron flux in the LHD torus hall and in the same order as the neutron flux in the basement level of the torus hall. The status of all components is monitored remotely from the control room. The results of neutron exposure test are summarized in Table 1. Transient effects due to neutron irradiation are observed on a PC, an IR camera, a web camera, APDs, PMTs and a PLC. Disconnection of the network is observed on the PC at neutron flux of $3 \times 10^{5} \mathrm{~cm}^{-2} \mathrm{~s}^{-1}$. The frequency of this effect is once per 11 hours. If we assume that the frequency increases linearly with the neutron flux, the PC placed in the torus hall without any shield will experience a disconnection of the network up to once per four shots at the maximum neutron emission discharge of LHD. Here, we assume that the frequency increases linearly because the both ionisation and displacement damage due to radiation on the semiconductor materials increase linearly with the radiation fluence [12]. Note that we classify the effect as transient because the disconnection of the network recovers due to the reboot. Temporal dead pixels 
due to neutrons appear on the IR camera (Fig. 4). We observed four dots per 3 hours at neutron flux of $7 \times 10^{5} \mathrm{~cm}^{-2} \mathrm{~s}^{-1}$. Note that the temperature shown in dead pixels is always zero. The IR camera will be installed on the upper port of LHD where expected maximum neutron flux is $10^{10} \mathrm{~cm}^{-2} \mathrm{~s}^{-1}$. If the number of dots linearly grows as neutron flux, the number of dead pixels due to neutrons will reach 2 dots per shot. Note that the effect is transient because the dead pixels due to neutrons recover due to reboot. The loss of the image is obtained on the web camera at the neutron flux of $3 \times 10^{6} \mathrm{~cm}^{-2} \mathrm{~s}^{-1}$ whereas on the neutron flux of less than $3 \times 10^{5} \mathrm{~cm}^{-2} \mathrm{~s}^{-1}$ the image transfer has no problem. At first, green on the web camera disappears (Fig. 5), therefore, the movie completely disappears even though the connection between the web camera and a PC is stable. The effect is observed once per 11.5 hours, and the expected failure rate in the LHD torus hall is once per forty shots. In PMTs and APDs, we observed neutron-induced pulse with frequency of $23 \mathrm{~Hz}$ and $1.5 \mathrm{~Hz}$, respectively. If we put the PMTs and APDs near LHD, where the neutron flux will be $10^{10} \mathrm{~cm}^{-2} \mathrm{~s}^{-1}$, we will obtain neutron induced pulse with frequency of $115 \mathrm{kHz}$ and $7.5 \mathrm{kHz}$, respectively. We observed neutroninduced error at neutron flux of $3 \times 10^{6} \mathrm{~cm}^{-2} \mathrm{~s}^{-1}$ whereas at neutron flux of $3 \times 10^{5} \mathrm{~cm}^{-2} \mathrm{~s}^{-1}$ no error is observed on PLC modules. Neutron-induced errors occurred on the PLC three times per 9 hours (Fig. 6). The behaviour of the AC output module is different in each case. In the first case, the output voltage becomes zero when disconnection of the network occurs. However, the second time, the output voltage stays the same even though the network is disconnected. Moreover, the third time, the output voltage shows $10 \mathrm{~V}$ (maximum) when disconnection of the network occurs. Note that no permanent effect is observed in this experiment. 


\section{Gamma-ray irradiation test}

Gamma-ray irradiation tests are performed in the Nagoya University Cobalt-60 irradiation facility [13]. A PC, two media converters, two optical flow meters, two isolation amplifiers, a web camera, and two PLCs were irradiated (Fig. 7). The gamma-ray dose rate to the silicon (Si), which is a major ingredient of electronics components, evaluated by calculation on the day of the experiment $(2015 / 7 / 14)$ is $190 \mathrm{~Gy} / \mathrm{h}$ at $20 \mathrm{~cm}$ from the source, $86 \mathrm{~Gy} / \mathrm{h}$ at $30 \mathrm{~cm}$ from the source, and $30 \mathrm{~Gy} / \mathrm{h}$ at $50 \mathrm{~cm}$ from the source. The results of gamma-ray exposure are summarized in Table 2. No transient effect is seen except for the web camera and the analog terminal of the PLC at the dose rate of $38 \mathrm{~Gy} / \mathrm{h}$. The PC is broken at the integrated gamma-ray dose of 224 Gy. The connection of two media converters is stable after the integration dose of $320 \mathrm{~Gy}$. The signal of two optical flow meters is unchanged after the integration dose of $240 \mathrm{~Gy}$. The output signal from the isolation amplifier is stable after the integration dose of $112 \mathrm{~Gy}$. The dot noise due to gamma-ray is observed on web camera. This effect is only observed during the gamma-ray exposure. The output signal from PLC1 and PLC2 is monitored by a PC through the network. The increase of the offset of the analog output is observed from the beginning of the analog output from analog output module (DA04-IN) of PLC1 (Fig. 8). The output signal disappears when the integrated dose reaches 86 Gy, because the connections between the PLC1 and the PC is broken. The mismatch of input and output signals is observed on analog output module (CS1W-DA08V) and Devicenet input module (CS1W-DRM21-V1) of PLC2 at 95 Gy (Fig. 9 a) whereas DA output and AD input signals are same (Fig. 9 b). Both signals disappear at 112 Gy because of CPU-module broke. We tried to reboot both PLCs by inserting and pulling out the power supply plug of the electric apparatus. However, there was no reaction from both PLCs. We found that modules of the PLC are broken around the dose of 100 Gy. This is comparable with the dose in the LHD torus hall over nine years, and the dose is one order smaller than the threshold of the 
PLC in the 1990s [5]. It is considered that short-circuits occur more easily by the ionization effect of radiation at the narrower electrode gap in the highly integrated devices. In previous data, transient effects are dominant in the electrical devices by gamma-ray irradiation. However, permanent damages have been observed in several digital devices, which is probably due to short-circuits at the narrow electrode gap. Also, radiolysis effects of gammarays in the $\mathrm{SiO}_{2}$ layer such as a radiation induced electrical degradation (RIED) should be considered.

\section{Summary}

In summary, effects of neutron and gamma-ray exposure on electronic equipment currently used in the LHD torus hall are studied in OKTAVIAN, FNL, and Nagoya University Cobalt60 irradiation facility. The irradiation on PCs, media converters, the IR camera, an MPPC, web cameras, APDs, PMTs, PLCs, optical flow meters, and isolation amplifiers are performed. In neutron irradiation test, the disconnection of the network is observed on the PC at neutron flux of $3 \times 10^{5} \mathrm{~cm}^{-2} \mathrm{~s}^{-1}$, and on the PLC at neutron flux of $3 \times 10^{6} \mathrm{~cm}^{-2} \mathrm{~s}^{-1}$. This neutron flux is equivalent to the flux at the basement level of the LHD torus hall. The experiment also shows that there is no effect on the PLC on the neutron flux below $3 \times 10^{5} \mathrm{~cm}^{-2} \mathrm{~s}^{-1}$. Neutroninduced dead pixels are observed on the IR camera. These dots disappear due to reboot. Neutron-induced signal is observed on APDs and PMTs. The pulse rate of these detectors in the LHD torus hall will reach $7.5 \mathrm{kHz}$ and $115 \mathrm{kHz}$, respectively, without a neutron shield. No effect is observed on the media converter and the MPPC at neutron flux of $3 \times 10^{5} \mathrm{~cm}^{-2} \mathrm{~s}^{-1}$ and neutron fluence of $8 \times 10^{9} \mathrm{~cm}^{-2}$. This neutron and gamma-ray irradiation test shows that highly integrated electronic components such as PLCs and PCs cannot be used in the torus hall without neutron shield, and equipment used in this experiment can survive nine years of deuterium operation in the torus hall if we consider the gamma-ray dose only, though the 
safety factor is low. Hence, we designed the neutron shield for the IR camera, and we moved PCs and PLCs as far as possible to the basement level of the torus hall and put several neutron shields made by the borated polyethylene for the safe operation of LHD deuterium experiments.

\section{Acknowledgements}

This work was partly performed with the support and under the auspices of the NIFS Collaboration Research program (KOAH033), by the LHD project budget (ULGG801), and by the Fusion Engineering Research project budget (FHH002). The authors are grateful to the OKTAVIAN, FNL, and Nagoya University Cobalt-60 irradiation facility operation groups for their excellent technical support.

[1] A. T. Ramsey, Rev. Sci. Instrum. 66 (1995) 871.

[2] A. Huber G. Sergienko, D. Kinna et al., Fusion Eng. Des., in press (available at http://www.sciencedirect.com/science/article/pii/S0920379617303915)

[3] T. Nishitani et al., Fusion Eng. Des. 42 (1998) 1-4.

[4] T. Iida, Ionizing Radiation 17 (1991) 3. (In Japanese)

[5] M. Sandor et al., JPL Publication 92-22 (1992).

[6] J. T. Goorley et al., LA-UR-13-22934. (Los Alamos National Laboratory, Los Alamos, 2013).

[7] H. D. Lemmel et al., IAEA-NDS-100, Rev. 11, (IAEA, Vienna, 2001).

[8] Y. Wu, FDS Team, Fusion Eng. and Des. 84 (2009) 1987-1992.

[9] Y. Wu, J. Song, H. Zheng, et al., Ann. Nucl. Energy 82 (2015) 161-168. 
[10] M. Baba et al., Nucl. Sci. Eng. 124 (1996) 228-242.

[11] I. Murata, Compendium of Neutron Beam Facilities for High Precision Nuclear Data Measurements, IAEA-TECDOC-1743, pp. 110-118, International Atomic Energy Agency (2014).

[12] C. Claeys, E. Simoen, "Radiation Effects in Advanced Semiconductor Materials and Devices", Chapter 2 Springer (2002).

[13] http://co60.nucl.nagoya-u.ac.jp 


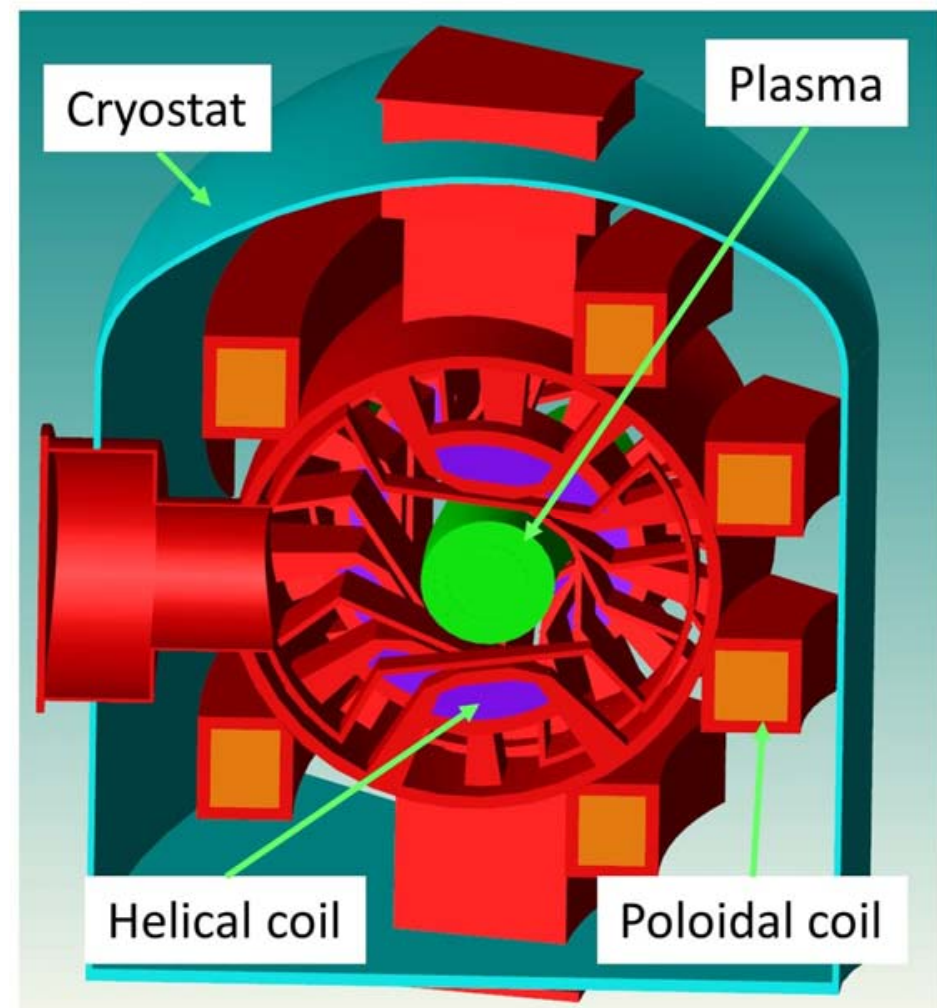

Fig. 1. MCNP Model of LHD. The figure is made with SuperMC $[8,9]$ 

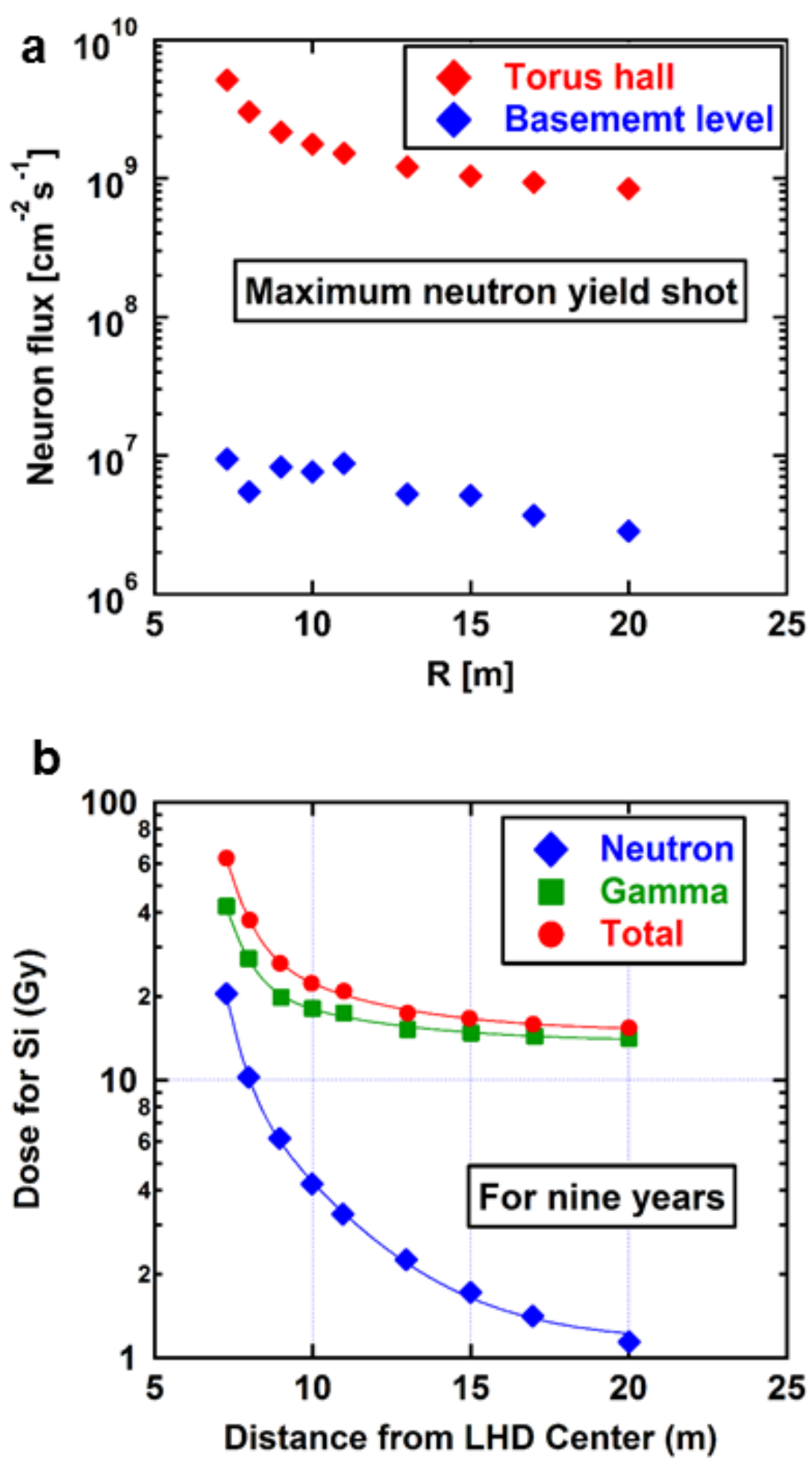

Fig. 2 a). Neutron flux profile in the LHD torus hall. b). Dose profile for Si in the LHD torus hall. 


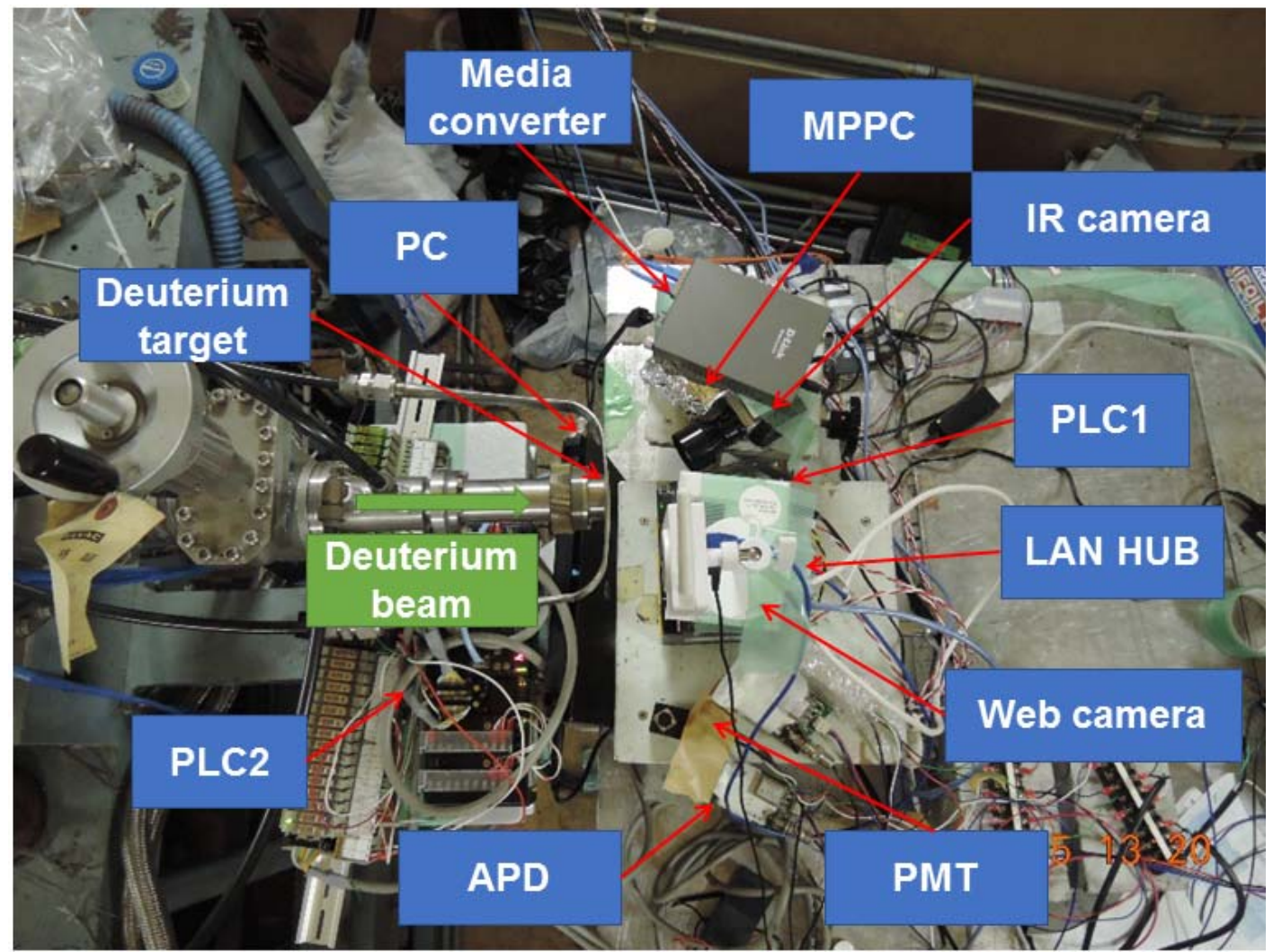

Fig.3 Arrangement of neutron irradiation test in OKTAVIAN. 
$\mathbf{a}$

Before irradiation

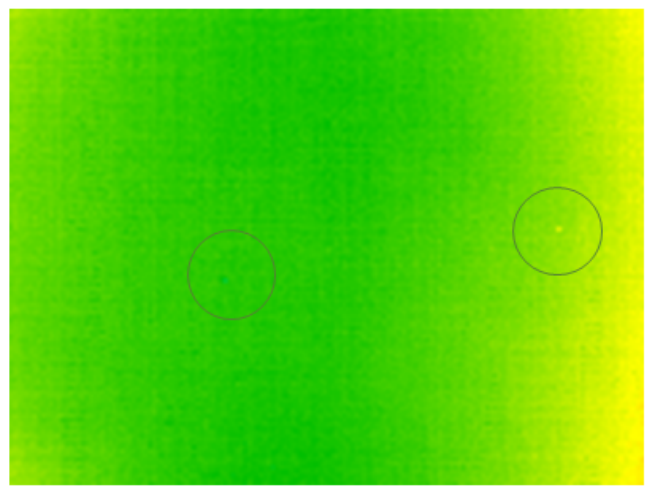

Dots appeared before irradiation b After irradiation

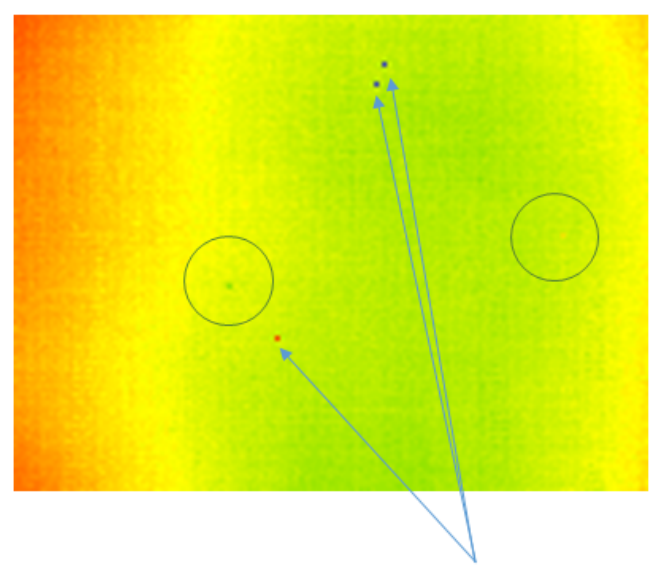

Neutron induced dots (disappear after reboot)

Fig.4 IR camera image taken (a) before neutron irradiation and (b) after neutron irradiation. 

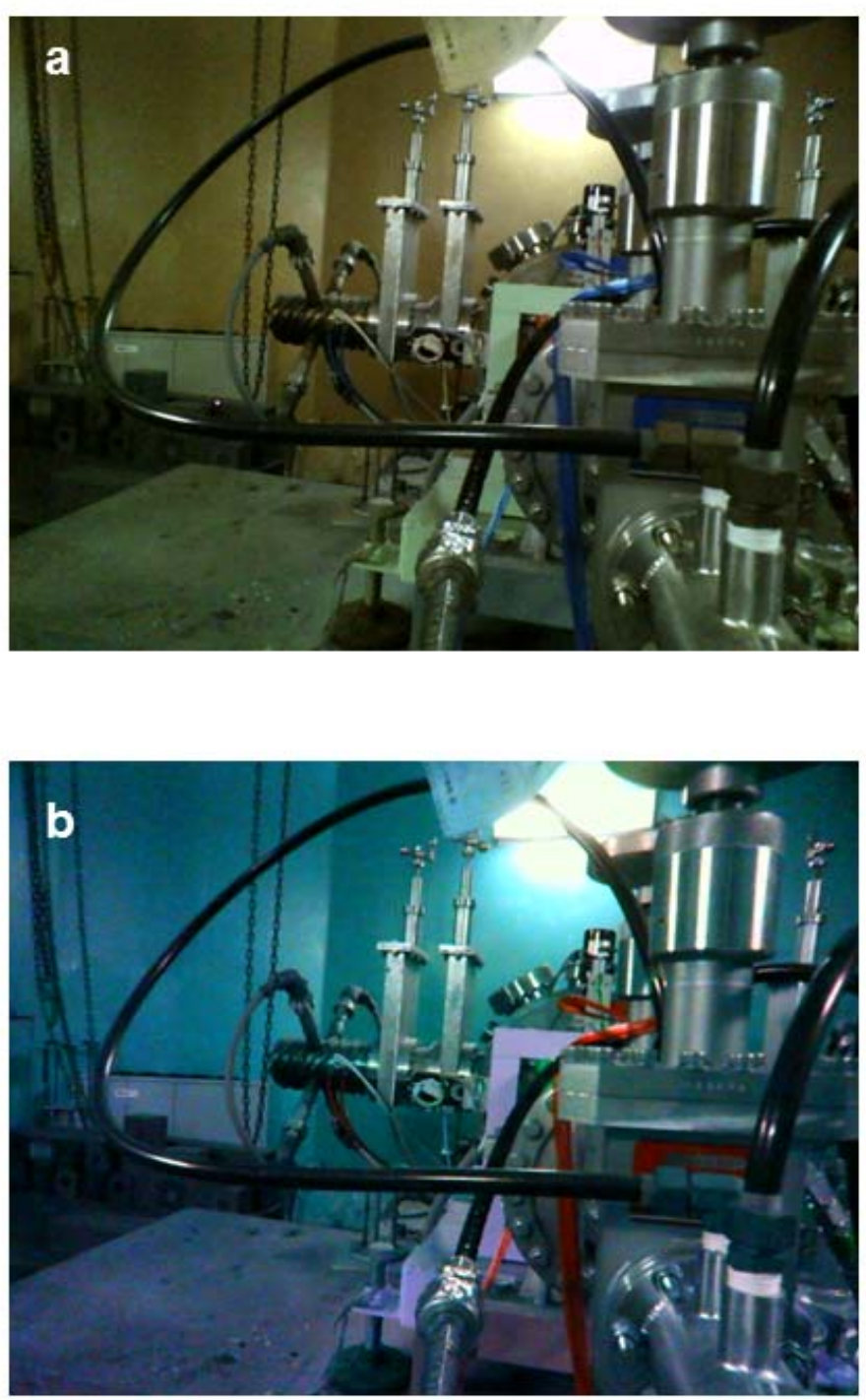

Fig. 5 (a) Normal web camera image. (b) Green on web camera disappears due to neutron irradiation. 


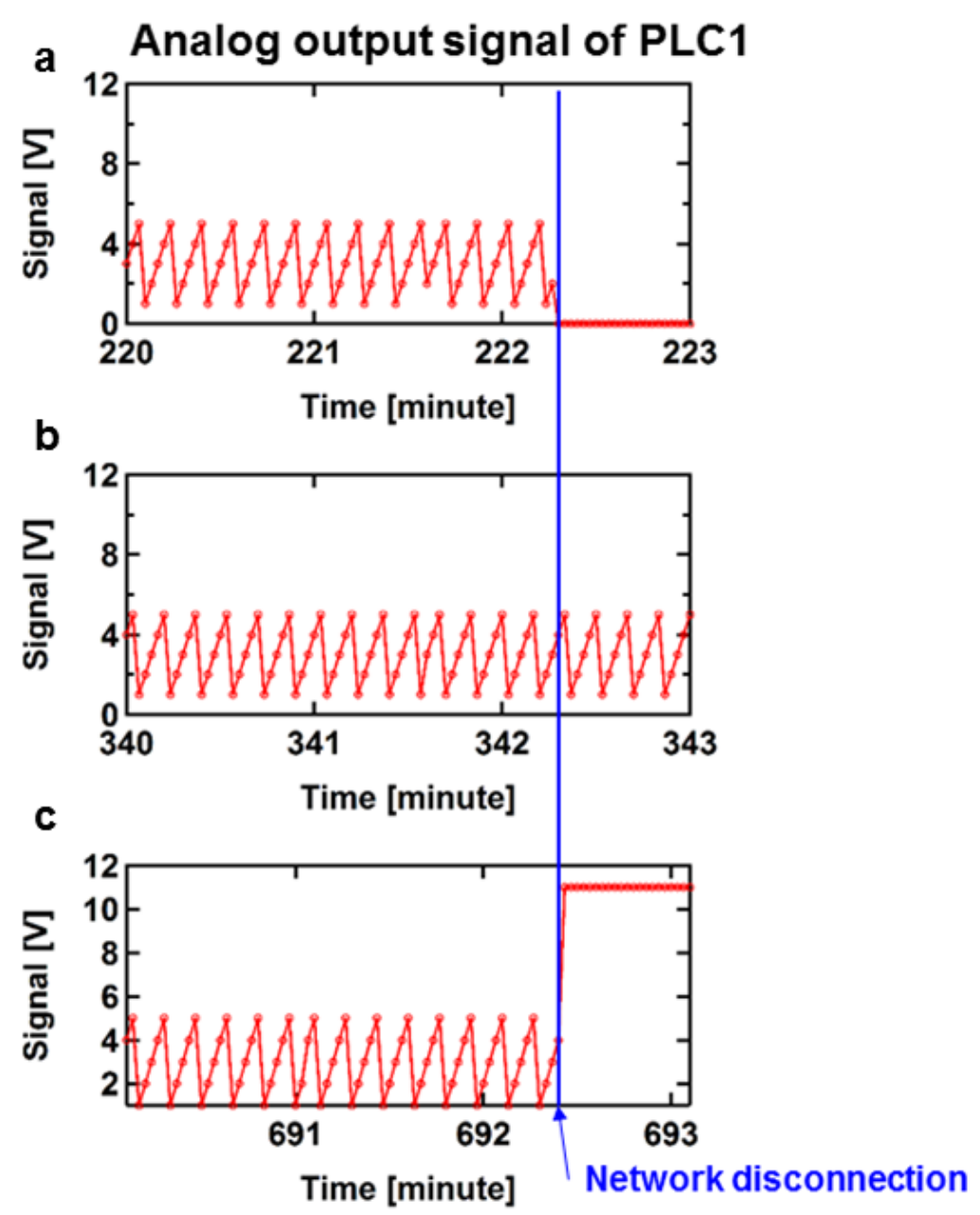

Fig. 6. Time evolution of analog output signal of PLC1. (a) The output voltage becomes zero when disconnection of the network occurs. (b) The output voltage stays the same even though the network is disconnected. (c) The output voltage shows $10 \mathrm{~V}$ (maximum) when disconnection of the network occurs. 


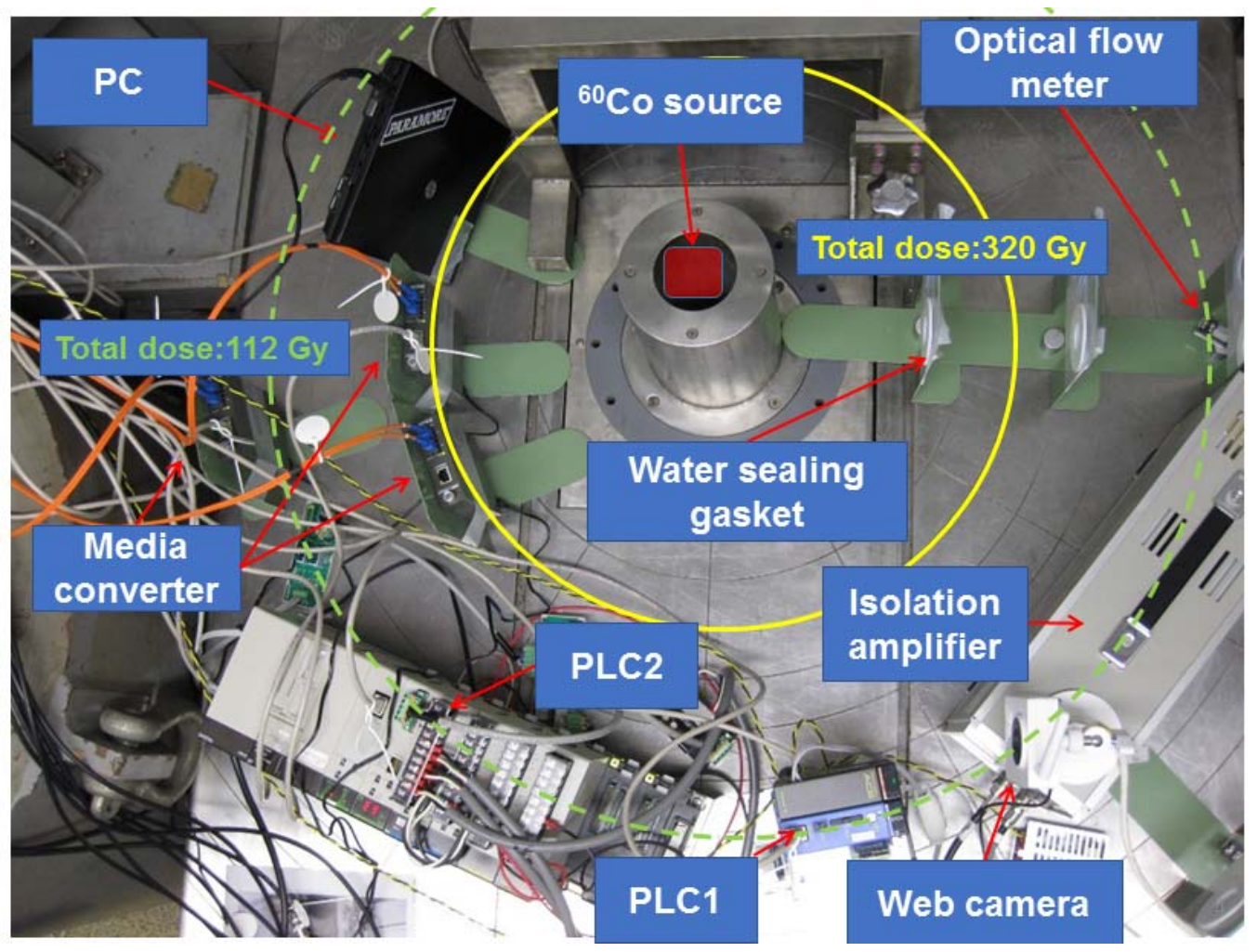

Fig. 7. Arrangement of gamma-ray irradiation test in Nagoya University Cobalt-60 irradiation facility 


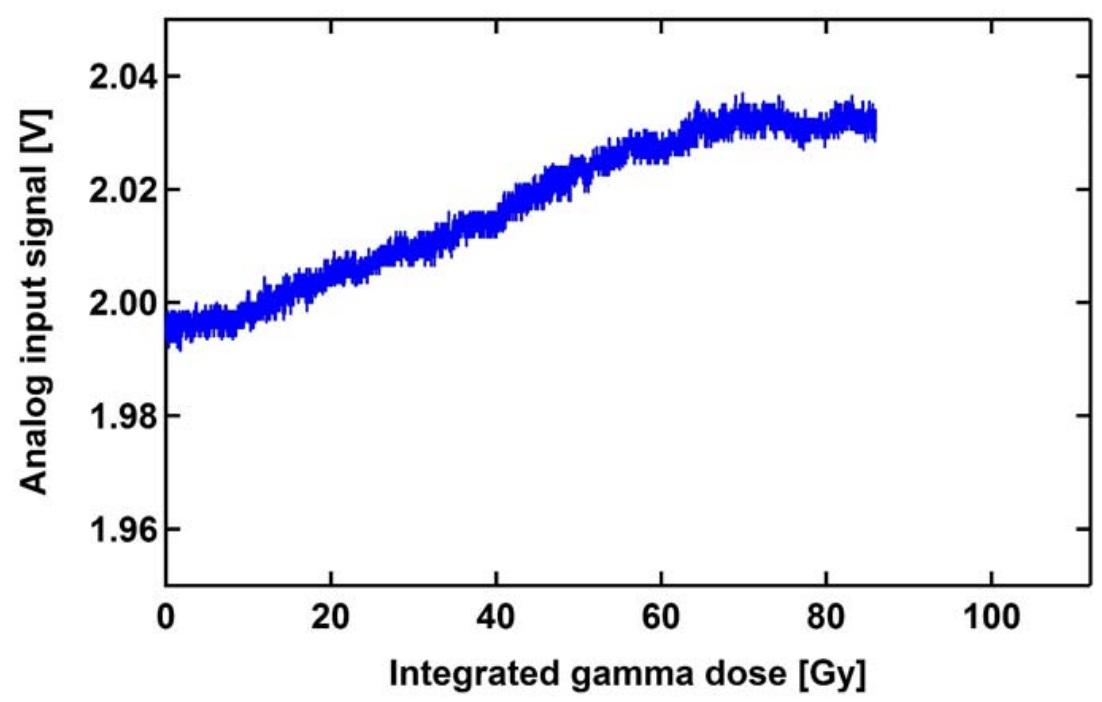

Fig. 8 Offset increase on analog output module due to gamma-ray irradiation. 


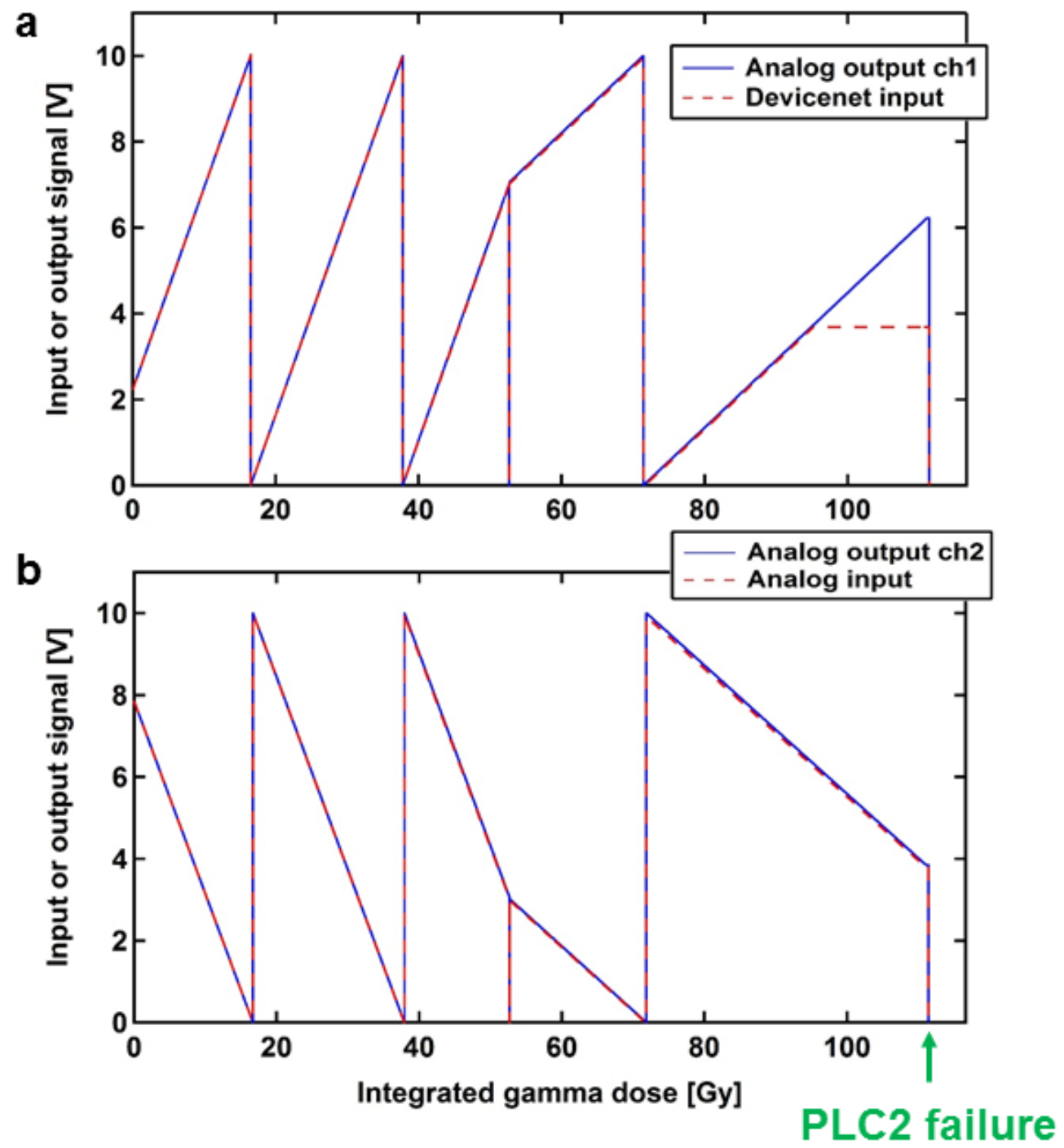

Fig. 9 (a) The mismatch of input and output signals is observed. (b) Both signals have same trend until PLC2 broken. 
TABLE 1. Summary neutron irradiation experiment on electronic equipment of LHD

\begin{tabular}{|c|c|c|c|c|c|c|c|}
\hline \multicolumn{2}{|c|}{ Component } & Manufacturer & Model number & $\begin{array}{c}\text { Neutron } \\
\text { flux } \\
{\left[\mathrm{cm}^{-2} \mathrm{~s}^{-1}\right]} \\
\end{array}$ & $\begin{array}{c}\text { Neutron } \\
\text { fluence } \\
{\left[\mathrm{cm}^{-2}\right]}\end{array}$ & $\begin{array}{c}\text { Transient } \\
\text { effect }\end{array}$ & $\begin{array}{c}\text { Permanent } \\
\text { effect }\end{array}$ \\
\hline \multirow{2}{*}{\multicolumn{2}{|c|}{ Media converter }} & $\begin{array}{l}\text { Hewlett- } \\
\text { Packard }\end{array}$ & HP Mini 5103 & $3 \times 10^{5}$ & $4 \times 10^{9}$ & $\begin{array}{c}\text { Network } \\
\text { disconnection } \\
\text { (Once) }\end{array}$ & Not observed \\
\hline & & D-Link & DMC-700SC & $7 \times 10^{5}$ & $8 \times 10^{9}$ & Not observed & Not observed \\
\hline \multicolumn{2}{|r|}{ IR camera } & Indigo & Omega & $7 \times 10^{5}$ & $8 \times 10^{9}$ & Dots appeared & Not observed \\
\hline \multirow{2}{*}{\multicolumn{2}{|c|}{ Web camera }} & $\begin{array}{l}\text { Hamamatsu } \\
\text { photonics }\end{array}$ & $\begin{array}{l}\text { C13366- } \\
\text { 1350GA }\end{array}$ & $7 \times 10^{5}$ & $8 \times 10^{9}$ & Not observed & Not observed \\
\hline & & I-O DATA & TS-WLCAM & $3 \times 10^{6}$ & $3 \times 10^{10}$ & $\begin{array}{l}\text { Dots appeared } \\
\quad(<1 \mathrm{~Hz})\end{array}$ & Not observed \\
\hline \multicolumn{2}{|r|}{ APD } & $\begin{array}{c}\text { Hamamatsu } \\
\text { photonics }\end{array}$ & C12703-01 & $2 \times 10^{5}$ & $2 \times 10^{9}$ & Pulse (1.5 Hz) & Not observed \\
\hline \multicolumn{2}{|r|}{ PMT } & $\begin{array}{c}\text { Hamamatsu } \\
\text { photonics }\end{array}$ & H10723-210 & $2 \times 10^{5}$ & $2 \times 10^{9}$ & Pulse $(23 \mathrm{~Hz})$ & Not observed \\
\hline \multirow{4}{*}{$\begin{array}{l}\mathrm{P} \\
\mathrm{L} \\
\mathrm{C} \\
1\end{array}$} & $\mathrm{CPU}$ & \multirow{4}{*}{ YOKOGAWA } & PU10-0S & \multirow{4}{*}{$3 \times 10^{6}$} & \multirow{4}{*}{$3 \times 10^{10}$} & $\begin{array}{c}\text { Network } \\
\text { disconnection } \\
\text { (three times) }\end{array}$ & Not observed \\
\hline & Power & & SP71-4S & & & Not observed & Not observed \\
\hline & Analog input & & AD04-0V & & & Not observed & Not observed \\
\hline & Analog output & & DA04-1N & & & Various effects & Not observed \\
\hline \multirow{9}{*}{$\begin{array}{l}\mathrm{P} \\
\mathrm{L} \\
\mathrm{C} \\
2\end{array}$} & $\mathrm{CPU}$ & \multirow{9}{*}{ OMRON } & CJ2M-CPU31 & \multirow{9}{*}{$3 \times 10^{5}$} & \multirow{9}{*}{$4 \times 10^{9}$} & Not observed & Not observed \\
\hline & Power & & CJ1W-PA205C & & & Not observed & Not observed \\
\hline & Analog output & & CJ1W-DA021 & & & Not observed & Not observed \\
\hline & Analog input & & $\begin{array}{c}\text { CJ1W-AD041- } \\
\text { V1 }\end{array}$ & & & Not observed & Not observed \\
\hline & Relay output & & CJ1W-MD231 & & & Not observed & Not observed \\
\hline & $\begin{array}{l}24 \mathrm{~V} \mathrm{DC} \\
\text { power }\end{array}$ & & S8VK-G01524 & & & Not observed & Not observed \\
\hline & $\begin{array}{l}\text { Analog } \\
\text { terminal }\end{array}$ & & DRT2-AD04H & & & Not observed & Not observed \\
\hline & $\begin{array}{c}\text { I/O relay } \\
\text { terminal input }\end{array}$ & & G7TC-ID16 & & & Not observed & Not observed \\
\hline & $\begin{array}{l}\text { I/O relay } \\
\text { terminal } \\
\text { output }\end{array}$ & & G7TC-OC16 & & & Not observed & Not observed \\
\hline
\end{tabular}


TABLE 2. Summary of gamma-ray irradiation experiment on electronic equipment of LHD

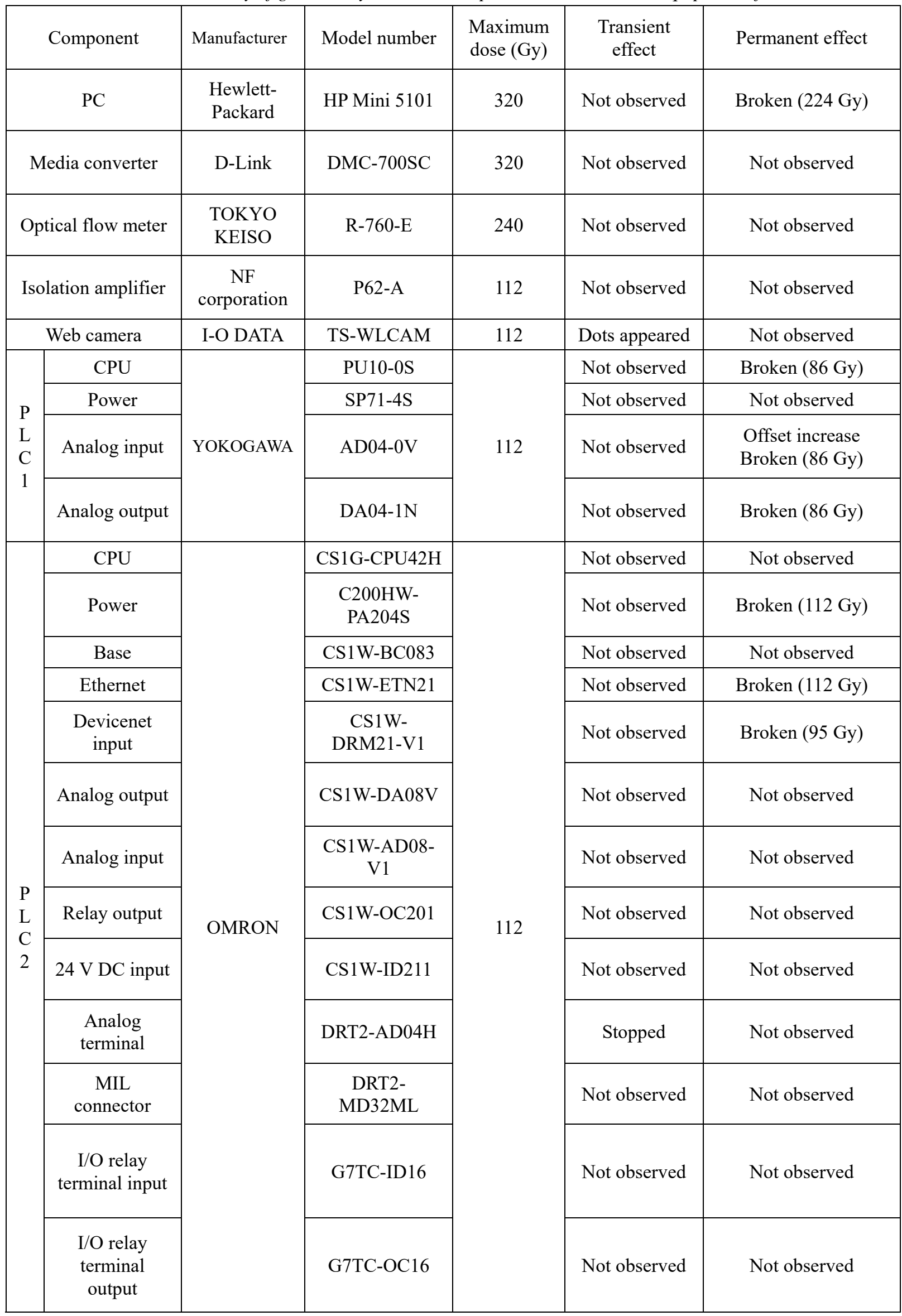


